\title{
Las nuevas subjetividades de los jóvenes chilenos
}

\section{The new subjectivities of young Chilean people}

\author{
Eugenio Miquel Prats* \\ Universidad Santo Tomás, Chile
}

(Recepción: Julio 2007 - Aceptación: Septiembre 2007)

\begin{abstract}
Resumen
La reflexión girará en torno a la temática del sujeto juvenil y su participación socio-política. Hay diferencias en el reconocimiento de los jóvenes como sujetos creativos e innovadores, o como expresión de peligrosidad y trasgresión del orden social; es decir, habría una constante tensión en la construcción de la ciudadanía juvenil en Chile. Existirían conflictos entre los discursos político-ideológicos que construyen la noción de juventud y el acontecimiento de las subjetividades juveniles. La dependencia estructural del sujeto social al tejido discursivo lo situaría como una producción de subjetividad capitalística, sujetos jóvenes producidos desde lo político. La inserción de los individuos en el orden colectivo sería concebida como una instancia traumática, como una catástrofe, una catástrofe social que institucionaliza al ser humano. Los jóvenes, como grupo invisibilizado, exigen ser sujetos ciudadanos desde lo informal, lo caótico, lo novedoso; la participación social y su capacidad de grupalidad permitirían producir nuevas subjetividades, nuevas singularidades.
\end{abstract}

Palabras Claves: Jóvenes, subjetividad, participación.

\begin{abstract}
The reflection will turn around thematic of the youthful subject and its social-political participation. There are differences in the recognition of the young people like creative and innovating subjects, or expression of danger and transgression of the social order; it's means, there would be a constant tension in the construction of the youthful citizenship in Chile. Conflicts between the political-ideological speeches would exist that to the notion of youth and the event of the youthful subjectivities construct. The structural dependency of the social subject to the discursivo weave would locate like a production of capitalística subjectivity, young people subject produced from the politician. The insertion of the individuals in the collective order would be conceived like a traumatic instance, a catastrophe, a social catastrophe that institutionalizes the human being. The young people, like invisibilizado group, demand to be subject citizens from the informal, the chaotic, the innovete thing; the social participation and its capacity of grupalidad would allow to produce new subjectivities, new singularities.
\end{abstract}

Key words: Young people, subjectivity, participation.

* Correspondencia a: Eugenio Miquel Prats. Escuela de Psicología, Universidad Santo Tomás - Temuco, Chile. Dirección: Manuel Rodríguez Nº60, Temuco, Chile. Teléfonos: 942200 / 9-9394468 E-mail: emiquel@ust.cl 
El siguiente texto comenzó como una aproximación conceptual sobre la relación entre la sociedad, sus diversos procesos democráticos y las implicancias a nivel de las subjetividades, sin embargo fue transformándose y construyéndose como una revisión reflexiva de hechos, con la intención de relatarlos, describirlos, y, a la vez, producirlos. Intentaré abrir y colarme en los espacios de hiancia (intersticios, intervalos, aperturas, quiebres) del sistema neoliberal, en pro de intercambios y resistencias a través del diálogo y del pensamiento crítico, con el optimismo de generar un trabajo de elaboración inter y transubjetivo. Busco hacerme parte de la circulación de un discurso que propone poner en relato, en texto, en diálogo, a través de lo intempestivo, lo novedoso, lo caótico, lo brutal, las versiones narradas y las acontecidas en las sociedades latinoamericanas, en Chile, en nuestros jóvenes.

Se trata de jugarse por una posición de pensamiento sobre las diferentes relaciones que se puede establecer entre lo ocurrido, lo que ocurre, o lo que ocurrirá, respecto de los individuos y su posicionamiento social, a modo de hacer re-aparecer la historia de los decires del mundo social, dando lugar a la aparición de lo nuevo, de lo aún sin hacer, de lo aún sin decir.

Los grupos sociales invisibilizados, en particular adolescentes y jóvenes, declaran y demandan acontecer como sujetos ciudadanos dentro de una sociedad civil que los construye y representa como incluidos-excluidos. La reconstrucción a través de la palabra se hace preponderante como reparación, y la palabra compartida re-crea una memoria histórica e identitaria que le devuelva al sujeto una noción de su propia existencia.

En un intento de contextualización, aludo a las palabras de Michelle Petit (2001), quien señala que en las sociedades tradicionales la identidad individual se construía desde el linaje familiar y de la pertenencia étnica, religiosa y social. Los hijos reproducían casi fielmente la vida de sus padres, todo dentro del marco de la familia patriarcal y monogámica, donde la autoridad del padre era ley. Un padre que hacía de puente entre el espacio público de lo socio-cultural, político, económico y el espacio privado de la familia, la ética, lo emocional, lo subjetivo.

Sin embargo, las sociedades clásicas devienen modernas a través de un sinnúmero de crisis, donde la modernidad se fundó, desarrolló e instaló a través de las constantes e inevitables transformaciones sociales, que no han provocado más que la casi completa desaparición de los marcos de referencia simbólicas e ideológicas desde donde se desarrollaba la vida, repercutiendo en las experiencias de vida de los individuos.

Tomando la lectura de Carlos Pérez Soto (1996), el sujeto clásico entró en crisis, por razones materiales y espirituales, constituyéndose en un sujeto moderno que acontecería como producto. Un sujeto moderno que media entre lo público y lo privado; sólo el padre es sujeto, habrían padres, en tanto individuos, que contienen la existencia de la familia. No habría subjetividad colectiva ya que la familia aparece como el espacio donde se crean las condiciones psíquicas y emotivas, que posibilitan, a la vez, la educación de los niños como seres adecuados, para que sean ciudadanos. Se aprecia como resultado un individuo autónomo, racional, productivo, responsable, es decir, un futuro padre de familia. Para este sujeto no cabe lo irracional, por tanto no habría espacio para la mujer, los niños, los ancianos, los locos, lo emoción pública, la fantasía, etc. El sujeto moderno se ha convertido en ciudadano, ligado a la estructura histórica y al liberalismo político y económico.

Si avanzamos en el desarrollo de la modernidad, la aparición del libre mercado y la ampliación del consumo han confirmado la fundación de nuevas subjetividades; en las palabras de García Canclini (1995), el paso de un sujeto ciudadano a un sujeto consumidor. La instalación de las comunicaciones como medio de contacto e intercambio entre los individuos, y su consiguiente marginación del acceso a la misma, potencian la enajenación y la decadencia del sentimiento y la realidad de la autonomía personal. De esta manera el sujeto moderno se ve arrojado a la incerteza, al azar del mercado, al desequilibrio social y a la división subjetiva. La promesa de libertad, la libertad moderna, es vivenciada como soledad y desencuentro, creando individuos solos, no capaces de asumir su autonomía, forzándolo a adherirse a novedosas y seductoras ideologías preestablecidas. 
La lógica del mercado produce un ingreso objetivo al trabajo, al consumo, a los derechos políticos y sociales; lo mencionado da cuenta de la crisis de la institución familiar (se ha disgregado la familia patriarcal y autoritaria), la cual se ha convertido en el lugar del conflicto, de disputas y diferencias insalvables. Se crearon, al interior de la familia, nuevos espacios de fuerza y legitimidad, de ser y desarrollo individual.

De esta forma la instancia íntima de la familia como generadora de psiquismos se ve cruzada, alterada y estructurada por la socialización temprana, contribuyendo a evitar la formación de una mismidad, conformando un aparato psíquico sin complejidad interna, hacia fuera, con ansiedad permanente de identificación externa, en donde los discursos inmediatos, placenteros, tranquilizadores, pseudoadaptativos y adictivos aparecen como el placebo perfecto desde donde construir una identidad. Es decir, estamos en presencia de sujeto sin interior, vaciado, sin culpas ni ideales, sin voluntad propia, viviendo apresuradamente la inmediatez del consumo. Se generan las nuevas enfermedades del alma.

Los individuos conllevan subjetividades que dan cuenta de una división, entre un espacio de la conciencia, un individuo socializado, y un espacio "oscuro", de momentos y situaciones en que se pierde el control, donde el sujeto no se reconoce a sí mismo. Pérez Soto (1996) confirma que el sujeto moderno no es realmente un sujeto, ya que su parte racional carece de mismidad, carece de Padres, tanto en la familia como en la sociedad.

Existiría una subjetividad dominante (europea) y una periférica (latinoamericana). Subjetividades características de los sectores integrados a la producción y los marginados de ésta. Lo que deseo resaltar es la forma en que se produce una integración a lo común, a un poder común, a una subjetividad común. Es decir, los denominados excluidos, lo son semánticamente, el hombre-blanco-occidental nombra y designa la identidad a la forma moderna. Los sujetos son construidos y desarticulados desde estas crisis, en donde se desconoce la historia anterior, repitiendo siempre los mismos problemas, la exclusión aparece como componente de la subjetividad, desde donde el marco normativo del sujeto moderno ha sido alterado.

Y, en nuestra época del fin de las ideologías, la desaparición de los clásicos referentes simbólicos, trastoca el sentido de ser y estar en el mundo a través de discursos, dispositivos y prácticas totalizantes, hegemónicas, es decir, globalizadas.

Hoy en día, cada uno de nosotros debe construir el sentido de su existencia, su identidad, su situación, en particular en la adolescencia y juventud, de la forma que mejor pueda, haciendo experimentos en busca de sentido, de valores, de puntos de referencia, de límites, allí donde los límites simbólicos están ausentes. Hago referencia a los intentos aislados, individualizados y fragmentarios de hacer una subjetividad, con todas las vicisitudes y riesgos que esto implica.

\section{Democracia}

Los procesos de transformación social, cultural e histórica, tanto a nivel mundial como a nivel local, han cimentado los caminos que me permiten comprender las vicisitudes por las cuales han circulado las constituciones democráticas de los países y sujetos latinoamericanos.

Para dar cuenta de las transformaciones mencionadas, me posiciono desde los planteamientos de Norbert Lechner (1990), que desarrollan la idea de un capitalismo en constante reacomodación, que moviliza e instaura la institucionalización a través de un nuevo orden internacional, promocionando los atractivos procesos de integración transnacional, desde donde se articularía la progresiva desintegración nacional de los pueblos latinoamericanos. Este movimiento estaría afectando localmente las bases estructurales de América Latina, en tanto el tejido social no tendría ya los referentes habituales, no tendría al alcance de la mano una memoria histórica propia, y por lo tanto, no podría construir ni proyectos a futuro, ni paradigmas teóricos ni modelos prácticos. La seguridad de los individuos comienza a aparecer como problemática de reflexión.

Individuos que se perciben sin historia propia, sin posibilidad de proyección, refieren evidentemente a la cuestión de la identidad. El sujeto latinoamericano históricamente construido y nombrado 


\section{LAS NUEVAS SUBJETIVIDADES DE LOS JÓVENES CHILENOS}

como otro, un otro salvaje, un otro indígena, un otro mestizo, entra en crisis; ya no sabe quién es, de dónde viene y para dónde se dirige, temblando la seguridad de su construcción histórica, vivenciando una inseguridad básica que trasunta a nivel colectivo como miedos sociales, en tanto traumas colectivos (tema que desarrollaré en la temática de las catástrofes sociales). Lechner (1990) afirma que los individuos latinoamericanos perciben amenazas veladas, violentas, sintiéndose temerosos y abandonados. Estoy haciendo referencia a dinamismos en el orden social que cuestionan este mismo ordenamiento.

A través de las transformaciones sociales se establece el riesgo donde todo parece posible, insertando la angustia y la incertidumbre en las relaciones, relaciones intersubjetivas. Es precisamente desde aquí, desde esta incertidumbre, que, según Lechner (1990), se funda la democracia moderna; es decir, los principios políticos desestiman las certidumbres del pasado, colocando los intereses globales y las instituciones de la sociedad en primer plano, en desmedro del desarrollo de los grupos y los individuos. Estoy enfatizando una problemática político-ideológica que dificulta la transacción de las subjetividades, ya que el ámbito del poder dice de una verticalidad, que dificulta y entrampa toda posible negociación y diálogo.

Tanto la historia como la realidad contingente nos dejan en medio de una sociedad latinoamericana compleja, desencantada, desarraigada. Continuando con Lechner (1990), el desgarro de esta sociedad, su malestar, muestra y deja en evidencia la cara oculta de la política, es decir, cómo la implementación y manipulación de lo político, de las ideologías, han instaurado el miedo de los individuos al nivel del desarraigo social, donde la ansiedad se ha popularizado como una pertenencia colectiva compartida, una angustia que trasciende la subjetividad individual, una angustia transmitida intersubjetivamente.

La democratización en América Latina enuncia una sociedad que no lograría conformarse y autoafirmarse como un orden colectivo que dé cuenta de una organización con principios y voluntades propias, libre de las prescripciones que garantizaban el orden establecido. Recalco la idea de una subjetividad sometida, controlada, vigilada y castigada, que institucionaliza la diferencia como un ejercicio de poder.

\section{Ciudadanía}

El anterior desarrollo sobre democracia tendría su anclaje en la relación que intentaré establecer entre lo político y la ciudadanía. Me inserto de lleno en la temática a través de la consideración de una "ciudadanía moderna". Garretón (1995, citado en Camacho, 2004) la define como la extensión de los derechos de los seres humanos fundados en la lógica de la diferencia, la que estaría otorgando la ilusión de definir y luchar por tales derechos. Sin embargo, como señalé, es sólo una ilusión, un deseo (producto de una falta, un vacío), ya que la posible puesta en escena de esta ciudadanía se ve frenada y negada por la exclusión, marginación y discriminación propia de la lógica de "lo diferente".

Lo anterior es sólo un preámbulo de las tensiones que se producen entre los discursos políticos y las nociones de una ciudadanía moderna; me atrevo a decir que evidencia y nombra la relación asimétrica establecida entre modernidad y subjetividad. Históricamente ciudadanía ha dicho del binomio derechos individuales y política; la compulsiva repetición de lo democrático se instituye como la apacible armonización de las exigencias de los discursos de la justicia y las demandas de una identidad social coherente.

Tomaré a Juan Sandoval Moya (2003) a modo de guía para profundizar esta problemática de la ciudadanía. Supuestamente el discurso de la ciudadanía marcaría la posibilidad que surja una nueva subjetividad liberal que pueda aspirar a la autonomía y al desarrollo de los individuos, en un intento de desligarse de la noción de sujeto súbdito (sujeto premoderno), promocionando nuevas categorías como género humano, derechos naturales y revolución democrática.

Agrego la idea de ciudadanía que ha construido Somers (1997, citado en Sandoval, 2003), en tanto ésta sería una compleja malla de relaciones cuya naturaleza es tanto pública como intersub- 
jetiva; se supone, nuevamente, que la ciudadanía se conformaría como una categoría conceptual, a partir de significados, narrativas y discursos, en un intento de transformarse en los distintos momentos históricos. Ahora bien, entiendo que esta compleja malla de relaciones ha creado sólo un imaginario de la ciudadanía, como un sistema de significaciones que se estabilizan en una categoría abiertamente cerrada.

Este imaginario moderno de ciudadanía, según Sandoval (2003), se sostendría desde dos discursos: por un lado, el liberal, donde los derechos civiles y políticos garantizan la libertad para participar en el capitalismo de producción; y, por otro lado, el social, que protege a los individuos desde el acceso a los derechos sociales y la igualdad de oportunidades.

Se estaría en presencia de un discurso sobre libertad e integración, un discurso sobre igualdad, aunque no necesariamente igualdad en poder. Se inserta una idea de sujeto ciudadano que no se ajusta a las representaciones de diversidad y diferencia, que permita reconocer las identidades culturales presentes entre los nuevos ciudadanos modernos, postergando, invisibilizando, o francamente reprimiendo otras formas de subjetividad.

Cernadas (2003) afirma que las transformaciones en la política se relacionaron con la pérdida de centralidad del Estado nacional como el articulador de la vida social, la crisis de los partidos, la ideología neoliberal, la subvaloración de la subjetividad, la vida cotidiana y las nuevas identidades socioculturales. Los constantes conflictos, los problemas y las tensiones relacionados con las identidades y las seguridades de los grupos han pasado a ser central en la movilización social y política de los ciudadanos. Como apunta González (2006, en Caldichoury, Cornejo y González, 2006) la ciudadanía y la participación ciudadana se constituirían desde una relación de tensión, como producto de la lucha entre los incluidos y los excluidos dentro de los escasos límites que propicia el mercado. Todo discurso sobre ciudadanía se define y reduce a un decir sobre los individuos y no para los individuos, se arma un andamiaje político-ideológico que estructura construcciones traumáticas de las subjetividades de los individuos modernos.

Planteo la responsabilidad epistemológica de re-pensar y re-construir el proyecto de participación ciudadana, reconociendo, como lo hace Sandoval (2003), el carácter bivalente que tienen la mayoría de las comunidades humanas, al constituirse como formas híbridas de un sector social explotado, con rasgos de una identidad social despreciada. La participación ciudadana implica el análisis de comunidades que se construyen, diferencian y desmarcan de la dependencia estructural, tanto económica como cultural.

\section{Catástrofes sociales}

El proyecto histórico de ciudadanía ligado a las estructuras políticas-democráticas de Latinoamérica, me obligan a colocar en el centro de la discusión la noción del "entre", en un intento se dar cuenta de lo que emerge en la relación individuos/colectivos: los individuos construidos traumáticamente desde lo colectivo, generan consecuente la aparición de lo inesperado en la estructura social establecida. Entonces, el tema de la seguridad individual y colectiva será comprendido y tramitado desde la lógica de lo catastrófico.

La relación entre modernidad y subjetividad pasa inevitablemente por diversos factores que dicen de lo social, lo cultural, lo económico, lo político, lo religioso, etc. En el intento de abordar un tema tan vasto y tan complejo como la subjetividad, me veo en la obligación de centrarlo en su implicación histórica, social e ideológica; si me refiero a lo humano, al individuo, al sujeto, lo hago desde su dependencia estructural del ámbito social. Un sujeto social que se desenvuelve en un tejido discursivo del cual forma parte, que lo refiere y lo construye como sujeto, como una singularidad situada y sitiada, es decir, en palabras de Guattari (2005), como una producción de subjetividad capitalística.

En esta línea, Alejandro Grimson (2001) sostiene que históricamente, los espacios comunes deben comprenderse como campos de interlocución en los que ciertos procesos de construcción identitaria son legitimadas en instancias de alianza y conflicto, y otros procesos de identificación son 
invisibilizados. En cada espacio cultural se han fundado formas específicas de articular y ocultar la diversidad, haciendo aparecer la diferencia cultural como una herramienta de discriminación; los conflictos sociales pueden llevar a inventar o crear supuestas diferencias culturales.

Daniel Vega (2000) afirma que el sufrimiento de la vida cotidiana tiene estructuras causales, con claras y específicas figuras y nombres, que permiten nombrar y señalar el padecimiento, haciéndolo visible y decible. Cada grupo humano construye su propia cultura, instituyendo sus formas de significar el mundo, produciendo sus propios significantes, sus signos, sus teorías, sus ideologías, sus ritos, sus zonas luminosas, sus zonas oscuras y sus claroscuros. Así, producirán sus visibilidades y sus invisibilidades, sus visibles y sus invisibles, sus decibilidades y sus indecibilidades, sus silencios y sus silenciados.

La inserción del individuo en la sociedad moderna es particularmente traumática, produciendo subjetividades individuales permanentemente determinadas y constituidas por discursos ajenos. Desde esta perspectiva, lo traumático es concebido como una catástrofe, una catástrofe social que institucionaliza al ser humano.

Entenderé por catástrofe social la cronicidad para quienes sufren, y su potencialidad virtual de quienes no la padecen. Así, estas catástrofes acontecerían como situaciones sociales que se tornan más crónicas que agudas, conservando su capacidad devastadora, jugándose en el espacio social, instrumentadas y avaladas desde el poder, aconteciendo como "efecto humano" (Waisbrot, 2003).

El autor afirma que la catástrofe social se diferencia de la catástrofe natural en la intervención de otro humano. El aparato psíquico se ve obligado a un trabajo que no sólo debe dar cuenta del daño sufrido, sino que debe al mismo tiempo encontrarle un sentido. Y si el puro sentido es la crueldad de otro humano, algo de lo irremediablemente inexplicable se volverá núcleo potencialmente desorganizante. La palabra devastación refleja el efecto, en la subjetividad colectiva y en la subjetividad individual, del fenómeno catástrofe social. El devenir del cuerpo social y de los individuos dice de las catástrofes sociales en tanto expresiones agudas y cotidianas, pero, a la vez, dice de lo cronificado y mudo en una cotidianidad en la que lo catastrófico resulta naturalizado.

Una las señales más claras e irrefutables del acontecer catastrófico dice justamente de no reconocerlo, de no visibilizarlo, de no discutirlo. Silvia Bleichmar (citado en Waisbrot, 2003) confirma la existencia de una naturalización de las catástrofes sociales o de las catástrofes históricas, su presentación como algo natural, como algo del orden de lo imposible de ser enfrentado. Ella confirma la definición de catástrofe en el plano social, incluyendo factores económicos, sociales y políticos; las catástrofes históricas o sociales son producidas por los mismos seres humanos, que manifiestan las relaciones políticas y los conflictos derivados del dominio y el poder en una sociedad de bienes. Desde una mirada psicoanalítica, catástrofe dice de la forma en que, abarcando a sectores importantes de una población, la incidencia traumática de la misma impone riesgos y efectos en la subjetividad de quienes la padecen.

La noción de subjetividad enlazada a lo traumático pone en jaque relevando la autopreservación y la autoconservación individual. Desde Bleichmar (citado en Waisbrot, 2003), lo traumático sería, por un lado, aquello que pone en riesgo las significaciones y representaciones en torno a la conservación de la vida y sus riesgos, y por otro lado, cómo la autopreservación y sus enunciados identificatorios se sienten en riesgo. Es decir, lo que afectaría al sujeto sería el modo en que significa su propia angustia de aniquilamiento, del tipo que fuera. Es en las catástrofes históricas donde se hace evidente la diferencia entre estos dos aspectos produciendo procesos de desidentificación de los lazos sociales.

Por lo tanto, es en este escenario que los seres humanos se ven obligados a contraponer la identidad a la autoconservación, cada uno siente que tiene que dejar de ser quien era para poder seguir ganándose la vida, para seguir existiendo. El caso más extremo de la contradicción entre autopreservación y autoconservación lo han marcado las situaciones históricas de terror, en las que los seres humanos han tenido que elegir entre vivir a costa de renunciar a los enunciados de base que lo constituyen, o morir para poder seguir siendo quienes eran en tanto sujetos simbólicos, sosteniendo el 
valor representacional de su propio ser. Las cadenas traumáticas se organizan desde una perspectiva en la cual el sujeto está implicado no sólo subjetivamente, sino ideológicamente. Lo traumático dice cómo el propio individuo lo ubica en su representación, además de cómo han ubicado el acontecimiento traumático las experiencias históricas generacionales que precedieron al sujeto (Bleichmar, citado en Waisbrot, 2003).

El sujeto y su dependencia estructural de lo socio-cultural-ideológico determinan maneras de vivenciar lo traumático, formas de reaccionar, de angustiarse, de organizar el miedo, de representarse al otro. Siguiendo a Bleichmar (2003), cada individuo estructura, respecto del traumatismo, una organización que le permite posicionarse en relación con la comprensión simbólica del mismo, comprensión implicada en lo representacional, en la ideología de su historia en el marco de la sociedad de pertenencia. Hoy en día se asiste a la aparición de estos fenómenos en la sociedad civil, en la cual un gran número de personas han perdido hasta la ilusión de salir de las condiciones de horror en que viven, y otros, viven mejor en lo inmediato, perdiendo toda representación del futuro. Lo traumático lleva a una disminución de los intercambios con el exterior. Este es el momento más grave y más improductivo, ya que es el momento en el cual el psiquismo entra en riesgo, como entran en riesgo también las posibilidades de construcción de cualquier perspectiva, compartida o individual.

\section{Juventud}

Desde aquí, se requiere de procesos reflexivos, delimitando un lugar específico de análisis que gire en torno a un grupo social particular, que permita dar cuenta de este lugar bivalente y de su consecuente constitución subjetiva. Plantear la posibilidad de pensar en los jóvenes, me permite posicionar la relación exclusión-inclusión respecto del mundo social adulto formal y racional; cito nuevamente a Sandoval (2003), en tanto las demandas y necesidades de los jóvenes nos direccionan hacia los ámbitos de integración estructural y de reconocimiento de sus manifestaciones culturales.

Una re-lectura de Larrosa (2004, citado en Kohan, 2004), en su abordaje de la infancia, facilita problematizar y complejizar el tema de la juventud, descubriendo la brutal relación que se ha establecido entre los jóvenes y los adultos. De esta manera, las distintas imágenes que se han construido en torno a la "juventud", resultan a tal grado enigmáticas para los adultos, que los jóvenes acontecerían como un espejo de los adultos, un producto de los miedos y esperanzas adultas, del coraje y la cobardía, de lo que creen los adultos que son y de lo que sienten que les falta, de lo que les gustaría ser y de lo que saben que nunca serán, de sus utopías y de las decepciones, de sus sueños y sus pesadillas, de sus logros y de sus fracasos, de su devenir en el tiempo, la memoria y el olvido, la repetición y la diferencia, la continuidad y la discontinuidad, el nacimiento y la muerte.

Los jóvenes chilenos han sido considerados siempre desde otros discursos, siendo una etapa, según Blanchard, dedicada a la adquisición de las condiciones para desempeñarse satisfactoriamente dentro de los roles adultos. Es decir, se propician los dispositivos y prácticas, a través de la paternidad, para que el adultocentrismo de la estructura social sea instalado en la subjetividad juvenil. De esta manera, la noción de juventud moderna se va construyendo, siendo el lugar desde donde los jóvenes comienzan a vivenciarse como tales, en específico, comienzan a constituirse como sujeto en la periferia de estar dentro y fuera al mismo tiempo.

Desde la sociología y la ciencia política se ha insistido en la necesidad de incorporar otras variables al análisis del fenómeno juvenil. Así, se ha mostrado con suficiente elocuencia que la juventud tiene significados muy distintos para las personas pertenecientes a cada sector social específico (varones y mujeres, pobres y no pobres, habitantes rurales y urbanos, entre otros) y que la juventud se vive de maneras muy diversas, según el contexto circunstancial en que las personas crecen y maduran (sociedades democráticas o autoritarias, tradicionales o modernas, agrarias o industrializadas, laicas o religiosas, u otras). Es imprescindible ubicar el discurso sobre los jóvenes desde y para los jóvenes.

Lo anterior me lleva a rescatar el discurso sobre una juventud que dependiendo de su contexto se autodefinirá, dejando de lado las categorías preestablecidas que tienden a uniformar el abordaje en relación a la juventud. 


\section{LAS NUEVAS SUBJETIVIDADES DE LOS JÓVENES CHILENOS}

Al conceptuar a la juventud desde lo cultural, según Reguillo (2000), los jóvenes aparecen como un grupo activo, cambiante y discontinuo, generándose, a través de industrias culturales, espacios para la producción, reconocimiento e inclusión de la diversidad juvenil. Por otro lado, Wrob (2003) afirma que la teoría sobre la constitución del sujeto y de su identidad permite plantear que la juventud no es una etapa natural del desarrollo humano, sino una categoría construida socialmente, y encuentra su sentido en un espacio cultural determinado; es por tanto, una construcción cultural, una forma de comportamiento social que debe ser vista fundamentalmente como resultado de la cultura occidental y consecuentemente de la formación de la sociedad industrial moderna.

Como ya señalé, la juventud es una categoría construida, es más, confirmo la idea desde lo planteado por Bourdieu (1990), quien remite a la juventud a las relaciones de poder entre las generaciones, es decir, los jóvenes son los que luchan por el poder frente a los viejos. La juventud es una categoría exenta de neutralidad, que no alude a esencialismos, da cuenta de la manera en que las distintas sociedades perciben y valoran el mundo, y con ello a ciertos actores sociales. De esta manera, "las categorías, como sistemas de clasificación social, son también y fundamentalmente, productos del acuerdo social y productoras del mundo". (Reguillo, 2000).

María Lozano (2003) resalta cuatro tendencias que han marcado las representaciones en torno a lo juvenil, frecuentemente desde el mundo de los adultos y casi siempre desde la perspectiva institucional:

- Se concibe la juventud como una etapa desprovista de valor real por su carácter transitorio, y que no merece una inversión significativa de preocupación y de recursos. La juventud solamente adquiere su sentido en el futuro, y por ello a los jóvenes hay que contenerlos mientras llega su sensatez en la edad adulta.

- Los jóvenes tienen condiciones para absorber recursos, pero no para aportar ni cultural ni socialmente a los procesos de desarrollo de la sociedad. Se los considera como una carga y a veces como una afrenta a la cultura, no como una riqueza. La sociedad adulta hace un favor a los jóvenes al aportar o consentir recursos especiales para ellos, y cualquier demanda adicional se considera desproporcionada.

- Se idealiza a los jóvenes, ya sea colocándolos en el plano de lo peligroso para ser dominados, convertidos o contenidos, o bien situándolos en plano de lo puro y frágil. Esta percepción representa una forma de no querer ver la realidad de la juventud.

- Se homogeneíza a la juventud como si en todas partes las personas de una determinada edad fueran iguales, tuvieran las mismas necesidades o se debiera esperar lo mismo de ellas. Esta tendencia está presente en todas las anteriores.

Ubicar el discurso de los jóvenes se ha constituido todo un desafío para la modernidad, para los adultos y las instituciones; Oscar Dávila (2004) menciona que definir lo juvenil ha quedado en la insatisfacción, ya que existe la tendencia a abordarlo como un objeto de estudio desde diversos niveles como lo biológico, lo social, lo psicológico o lo fenomenológico, nunca de manera multidimensional.

Los discursos sobre los jóvenes muestran a un grupo etario definido y delimitado ideológica, teórica y disciplinariamente. Si existe un ámbito o campo que es cruzado (o dicho) por discursos externos, es la juventud. Las temáticas anteriormente planteadas (política y subjetividad) se convierten en los ejes nodales que definen la juventud. Siguiendo lo postulado por Muñoz (2000), se afirma que la infancia, la juventud y la adultez estarían definidas y construidas como categorías biológicas y sociales; de esta manera, la juventud sería una categoría asociada a sujetos diferenciados en su condición al interior del sistema social, en donde la sociedad acontece como campos de disputa, en donde las definiciones sobre la juventud tendrían un carácter político. 


\section{Intersubjetividad juvenil}

Los sujetos y sus procesos de singularización expresan la relación que se ha establecido con los discursos político-ideológicos de la institucionalidad. Reflexionar la producción de subjetividad, posiciona la vinculación entre participación y ciudadanía reformulando la comprensión de los modos de producción de los procesos y dispositivos, de los cuales los individuos son portadores.

Desde lo anterior, las democracias latinoamericanas estarían en constante crisis, lo que se aprecia en la participación política de los individuos. Así, desde García (2005), los individuos devienen individualistamente, distanciándose de la política partidista, centrando sus esfuerzos e intereses en el resguardo de lo propio y de la seguridad personal. Al mismo tiempo, lo político no estaría necesariamente desapareciendo, lo colectivo y lo asociativo estarían siendo satisfechos al interior de la sociedad civil de manera más bien informal. Las acciones participativas no políticas, que confirman la vuelta a la idea de la grupalidad, acontecerían desde la educación, los deportes, lo religioso, el voluntariado, grupos ambientalistas, juntas vecinales, etc. Se enuncia, se comienza a nombrar, un nuevo territorio que da cuenta, por un lado, de la no participación política, y, por otro, del rescate de la sociedad civil; territorios donde acontecen las producciones subjetivas.

Se hace difícil separar la juventud de subjetividad, siendo los jóvenes la máxima expresión de ésta y de las relaciones intersubjetivas, dada la construcción social que se hace de ellos, y siendo, a la vez, el lugar desde el cual se ubican para acontecer. Los jóvenes vivencian constante el quiebre que implica entrar en instancias de lucha con el discurso racional y adulto que los obliga. Estoy refiriéndome a una lucha por la dominación y el poder que marcará el acontecer subjetivo del joven.

Se hace necesario abordar los elementos constitutivos de esta discusión como un todo, considerando lo económico, lo político, lo sociológico, lo psicológico, lo afectivo, lo mitológico, como un tejido interdependiente entre el objeto de conocimiento y su contexto. Los jóvenes en sus relaciones intersubjetivas se ven imbricados en un contexto que los determina y los construye como sujetos, en donde el psiquismo estaría alejado del equilibrio, no cesando de pronunciarse, siendo caótico, en constante turbulencia. Si existe un lugar que se vincula al psiquismo es la historia, la que destruye y crea un movimiento en la subjetividad.

Desde Hornstein (2003), el objeto es un sujeto, algo fuera de su dominio; los otros, tarde o temprano, suave o violentamente, impondrán su modalidad y se rehusarán a un lugar que no quieren o no pueden ocupar. Toda relación implica conflicto. Cuando la relación del sujeto con lo externo se vuelve desorganizante, se tiende al ostracismo o a la entrega total en el hedonismo y la superficialidad de las relaciones simbolizantes. La reconstrucción posmodernista de la subjetividad ha descentrado a la psique de la inserción en el orden socio-simbólico, sin embargo, este descentramiento del sujeto no tendría razón de impedir un compromiso reflexivo con los otros y con las diversas prácticas colectivas.

El sujeto joven no es una sustancia, sino un devenir en las interacciones. Las nociones de historia y vínculos serían los pilares fundamentales para construir una perspectiva transformadora de la experiencia en el mundo, conceptual y sensible. La noción de historia no es una repetición ni el despliegue de lo contenido en el pasado, sino una noción ligada a la creatividad, el ruido, el azar, el otro, lo diferente, serían fuente de una radical novedad en la subjetividad.

Esta concepción de la subjetividad moderna dice de los jóvenes y las diversas perspectivas sobre la juventud definen diferentes tipos de sujetos jóvenes. Como ya se mencionó anteriormente cuatro tendencias que definen la juventud contribuyen a construir las diferentes subjetividades de los jóvenes. Jóvenes como sujetos en tránsito hacia una condición de actores sociales propiamente tales, adecuados, correctos y sometidos; como sujetos con una especificidad cultural de recursos y expresiones propias de su condición de actores juveniles; como sujetos que se constituyen como recursos para un futuro esplendor; y como sujetos peligrosos y riesgosos para el proyecto modernizador.

Los jóvenes se encontrarían entrampados entre discursos, conformados psíquicamente desde el conflicto, vivenciando su juventud como una época traumatizante, caótica, aconteciendo catastrófi- 
camente en su inserción social. Las imágenes sobre los jóvenes, desde los discursos político y cultural, encierran una juventud tensionada psíquicamente, sin referentes históricos y simbólicos que le permitan resolver el nudo de la integración y la diferencia. La palabra final y verdadera respecto de los jóvenes es del adulto, no siendo considerados como sujetos, sino hasta que alcanzan los parámetros definidos como adecuados desde el discurso hegemónico de la modernidad y lo neoliberal.

Los jóvenes en su intento de diferenciarse y continuar con su camino de construcción identitaria, buscan alternativas en los pliegues, repliegues y quiebres que permite el discurso dominante. La mal llamada sub-cultura juvenil dice precisamente de su necesidad de relacionarse, de conformar-se y desplegar-se como sujetos de un decir, que no es sub, ni alternativo, ni disruptivo sino sólo cuando es nombrado así desde el discurso del poder. El requerimiento del otro en lo intersubjetivo demuestra no sólo el hecho de diferenciarse del mundo adulto, o ir en búsqueda de la propia identidad, sino de hacer historia en el presente, a modo de re-significar experiencias compartidas, de consolidar lo colectivo, de generar instancias de simbolización desde su lugar de ciudadano: sus modos sub, nos señalan un posicionamiento político. Sus actos son políticos en tanto toma de posición, hacen evidente la imperiosa vigencia de crearse un lugar como sujetos de un mundo social del cual no quieren ni pueden permanecer en la periferia, ni en la doble contingencia de sentirse incluidos exclusivamente.

La experiencia juvenil dice de reunirse con sus pares, en organizaciones informales y contestatarias al sistema dominante, de hacer ciudadanía ejerciendo su rol y derecho como sociedad civil.

En Chile se han ido construyendo nuevas identidades y comunidades que llenan el vacío dejado por desafectación producida por la política. Formas periféricas que han ganado espacios centrales, al afectarse por las particularidades y fragmentarias experiencias de la vida en sociedad. La desafección ciudadana ha generado la puesta en escena de instancias más allá de la política, las que se han posicionado dentro de lo político, con decires y actos declarativos y políticos, que se despliegan en particulares formas de participación, experiencia y lenguaje.

Caldichoury, Cornejo y González (2006) plantean que la participación juvenil, dentro del marco de lo neoliberal, se daría en un nivel de la macro político, es decir, una participación orientada a la realización de cambios en la estructura económica y política sin un proyecto cultural o de construcción de subjetividades; y en un nivel micro político, donde la participación busca modificaciones estructurales a través de proyectos de construcción cultural y subjetividad.

La participación juvenil se plasma a través de organizaciones de autoeducación popular, colectivos juveniles entorno a lo cultural y lo educativo, grupos de autogestión e intervención en lo cotidiano, mediante la ocupación del tiempo libre y la actividad recreativa. Organización de centros de culturales, asambleas, bibliotecas populares. Se crean instancias de redes virtuales, grupos de hip-hop, okupas, construcción y recuperación de espacios públicos. Estoy haciendo mención al establecimiento de redes, redes territoriales, cual funcionamiento rizomático (Deleuze, 1997).

Se rescata la constitución de un "nosotros" y un "otros", dando cuenta de un entre que trasciende los límites tradicionales, re-significando símbolos ya conocidos y establecidos. Se está en presencia de una nueva identidad de resistencia, que articula a múltiples sujetos en torno a una lógica de acción política y sentido común. Se relevan los intereses de la organización social, colocando al colectivo como una organización informal que produce sujetos deseantes en relaciones horizontalizadas, desoligarquizadas.

\section{A modo de apertura}

En un intento de englobar lo dicho a lo largo del texto planteo que los discursos ciudadanos de la integración y la diversidad cultural en Chile, deben ser entendidos en su relación específica con las formas de concebir a los jóvenes, ya que se hace necesario pensarla como una vía de protección a un elemento marginal de la modernización. Del mismo modo, resulta diferente pensar el reconocimiento cultural de los jóvenes si son concebidos como sujetos creativos e innovadores, que si son concebidos como una expresión de peligrosidad y transgresión del orden social. Siguiendo a 
Sandoval (2003), es en esta tensión que toma forma el dilema de la construcción de la ciudadanía juvenil en Chile.

Pensar en una ciudadanía juvenil, implica problematizar dos nociones de por sí excluyentes para el discurso de la modernidad. Ciudadanía y juventud nos reposicionan en el debate de la reunión colectiva, de la integración y la diversidad, de la necesidad de lo histórico-social, de la construcción de un psiquismo individual y colectivo, de una re-significación del sujeto y su subjetividad. Esto enmarcado en el modelo político-cultural que escinde la historia de la proyección a futuro, que se contradice en el resaltar lo individual destruyendo y coartando las subjetividades. La noción de ciudadanía juvenil no representa lo mismo para todos, pero esencialmente no representa un valor simbólico a construir desde los jóvenes.

El cuestionamiento central gira en torno a cómo reformular una relación entre el aparato psíquico y la realidad en función de pensar un modo de organización que no se limita a reflejar la realidad ni a recibir sin resistencias la realidad, sino a procesarla, re-presentarla, a historizarla.

Este procesamiento de la realidad es el eje que permite entender cómo afecta lo traumático y la forma de recomposición, de producción de sentido. Lo real ingresa, angustia, produce algo, un algo que es necesario organizar y significar por medio de simbolizaciones de transición. Se sostiene que el rescate psíquico de estos padecimientos depende del saber, del trabajo profesional, de las puestas en escena de lo interdisciplinar, pero especialmente del considerarse como ciudadanos y sujetos de la cultura. No hay salud individual si no es posible la salud colectiva.

El intento juvenil está constantemente refiriéndose a la búsqueda de sentido desde un lugar de posibilidad y no de verdades absolutas, de acontecer como alguien que quiere decir algo para que sea escuchado por alguien. Sin embargo, la tan ansiada adultez se convierte en el discurso verdadero de cómo se deben hacer las cosas, por tanto de cómo deben ser los sujetos.

La realidad de la modernidad nos muestra un discurso sobre el deber ser y hacer, patologizando a la sociedad civil, en el que los procesos de des-subjetivación y des-identificación serían el producto de las acciones sociales y políticas. En la medida en que la subjetividad es superflua para el modelo económico, requiriendo piezas para el engranaje de la maquinaria y no sujetos pensantes y productivos, el efecto melancolizante que se inscribe dice de sujetos superfluos, infringiendo nuevos efectos traumatizantes en los sujetos.

Sin embargo, la misma modernidad entrega espacios que son aprovechados en la discusión y reflexión, tanto formal como informalmente, que permite ubicarnos desde lugares de decir, y sobre todo desde lugares de escucha, en tanto posibilidad de encuentro entre los individuos. Para el modelo, la subjetivación es ruptura, crítica, revolución, desarticulación del sistema consolidado, pensar es quebrar, romper. Subjetivar pasa por re-pensar los modos de conexión de lo disperso, de lo diverso, de lo diferente, de lo alterno, de lo sub, de lo joven. Proponiendo, en las certeras palabras de Vega (2004), una ética y una estética de la acción.

Los jóvenes no son nuevos actores, son los mismos jóvenes tensionados por las perspectivas del mercado neoliberal del trabajo y el adultocentrismo. Son los jóvenes que encuentran múltiples formas de resistencia y autogestión, que encontrarían nuevos lugares de expresión de sus demandas. Que se autoconstruyen desde líneas de pensamiento, desde líneas de acción, que dibujan figuras y prácticas transfigurativas, transformativas. Que generan posibilidades, territorios, de un nuevo orden social; que forjan deseos, como productores de deseo, deseo de recuperar lo perdido, lo no dicho, lo no hecho; es decir, un sujeto colectivo capaz de producir las condiciones de posibilidad para la invención. En fin intentos, gestos, balbuceos de recomposición del sentido común, a través de la participación con otros, haciendo ineludible el trabajo político permanente en la base social, apostando siempre hacia nuevas construcciones de subjetividad. 


\section{LAS NUEVAS SUBJETIVIDADES DE LOS JÓVENES CHILENOS}

\section{Referencias}

Blanchard, D. Juventud, población y desarrollo. Centro Latinoamericano y Caribeño de Demografía y División de Población, CEPAL. Revisado el 26 de octubre de 2007 en: http://www.eclac.cl/ publicaciones/Poblacion/3/LCG2113P/lcg2113P_cap1.pdf

Bourdieu, P. (1990). La juventud no es más que una palabra. En Sociología y cultura. México: Conaculta-Grijalbo, Colección Los Noventa.

Caldichoury, J. P., Cornejo, R., González, J. (2006). El derecho ciudadano a participar en la educación pública. Observatorio Chileno de Políticas Educativas. Santiago de Chile. Revisado el 08 de junio del 2007 en: www.observatorioeducacion.uchile.cl

Camacho, C. (2006). Democratización de la sociedad: Entre el derecho a la información y el ejercicio de la ciudadanía comunicativa. Sala de Prensa. Revisado el 11 de junio de 2007 en: http://www. saladeprensa.org/art563.htm

Cernadas, M. (2001). Cultura política: una herramienta compleja y sugerente de análisis de la realidad. Bahía Blanca, Argentina: Universidad Nacional del Sur.

Dávila, O. (2004). Adolescencia y Juventud: de las nociones a los abordajes. Revista Digital Última Década, No 21 CIPDA. Valparaíso, Chile.

Deleuze, G. y Guattari, F. (1997) Rizoma. Valencia, España: Editorial Pretextos.

Figallo, Muñoz y Salhe. (2003). Culturas Juveniles e Identidad. El caso de las barras bravas del fútbol. Tesis para optar al grado de licenciada en psicología. Universidad Diego Portales, Santiago, Chile.

García Canclini, N. (1995). Consumidores y ciudadanos. Conflictos multiculturales de la globalización. México: Ediciones Grijalbo.

Grimsom, A. (2001). Interculturalidad y comunicación. Colombia: Ediciones Norma.

Guattari, F. y Rolnik, S. (2005). Micropolítica. Cartografías del deseo. Buenos Aires, Argentina: Editorial Vozes.

Kohan, W. O. (2004). Infancia entre Educación y Filosofía. Barcelona, España: Alertes Ediciones.

Hornstein L. (2003). Intersubjetividad y clínica. Buenos Aires, Argentina: Editorial Paidós.

Lechner, N. (1990). Los patios interiores de la democracia, subjetividad y política. Buenos Aires, Argentina: Fondo de Cultura Económica.

Lozano, M. (2003). Nociones de Juventud. Revista Digital Última Década, Nº 18 CIPDA. Viña del Mar, Chile.

Pérez Soto, C. (1996). Sobre la condición social de la psicología. Santiago, Chile: LOM Ediciones.

Reguillo, R. (2000). Emergencias de culturas juveniles. Ediciones Norma.

Petit, M. (2001). La biblioteca, un espacio donde construir la propia ciudadanía. Conferencia en la XXI Feria del Libro Infantil y Juvenil, en México. Revisado el 10 de junio de 2007 en: http:// www.unescocat.org/ct/quisom/biblio/pdf/michelepetit.pdf

Sandoval, J. (2003). Ciudadanía y juventud: El dilema entre la integración social y la diversidad cultural. Revista Digital Última Década, № 19 CIPDA. Valparaíso, Chile.

Vega, D. et al. (2000). Travesías institucionales. Escritos de una subjetividad implicada en el campo social. Otras clínicas. Buenos Aires: Lugar Editorial.

Waisbrot, D. et al. (2003). Clínica psicoanalítica ante las catástrofes sociales. La experiencia argentina. Buenos Aires, Argentina: Editorial Paidós. 